\title{
LESSER BREEDS WITHOUT THE LAW
}

LEONARD R. N. ASHLEY

Brooklyn, New York

From such expressions as French leave and the French disease, Dutch courage and Dutch treat, his fine Italian hand in treachery or deceit, and so on, we learn something of the prejudices of our ancestors enshrined in the common vocabulary of the English language.

Here are a score of words referring to nations or nationalities. You are asked to guess them from their definitions. How many more can you add to the list? There is something of xenophobia, even contempt, for foreigners - - for not only England, but every Englishman is an is land - - here. Prejudices are obvious in other languages, too; in Paris, a waiter will call any man who fails to leave a tip the equivalent of Dane regardless of his nationality. Can you construct a similar list for French, German, etc? The answers to the following definitions can be found in the Answers and Solutions at the end of this issue.

1. A heavy or intimate kiss.

2. To lacquer.

3. To bind in goatskin.

4. One indifferent to culture.

5. Slang for coffee.

6. A British monetary unit.

7. To crush, or wound without killing.

8. A stately, processional dance.

9. A complicated cotillion dance.

10. To swindle or cheat.

11. To cheat by failing to pay a debt.

12. A violent, intractable person.

13. A failure, as of a play.

14. A slanting type face.

15. To mark mail for free delivery.

16. A Negro (early American dialect).

17. A donor who takes back his gift.

18. A spin given to a ball when hit.

19. To deal shrewdly or sharply in business.

20. To get into trouble. 